\title{
Correction to: Analysis and optimization of gear skiving parameters regarding interference and theoretical machining deviation based on chaos map
}

\author{
Peng Wang ${ }^{1} \cdot$ Fucong Liu ${ }^{1} \cdot \mathrm{Jia} \mathrm{Li}^{2}$
}

Published online: 20 October 2021

○) Springer-Verlag London Ltd., part of Springer Nature 2021

Correction to: The International Journal of Advanced Manufacturing Technology (2021) 112:2161-2175 https://doi.org/10.1007/s00170-020-06562-6

The original article contained a mistake.

The project number from National Natural Science Foundation of China in section Funding was wrote incorrectly to be 51175376, which should be 51775374 . The project 51175376 and project 51775374 both provided financial support for the research related to this paper, but project 51175376 had been concluded when this paper was submitted to the journal. The author wrote this number incorrectly due to carelessness.

Now, we amend the project number of National Natural Science Foundation of China to be 51775374.

We apologize for any problem caused by this mistake.

Publisher's note Springer Nature remains neutral with regard to jurisdictional claims in published maps and institutional affiliations.

The original article can be found online at https://doi.org/10.1007/ s00170-020-06562-6.

Peng Wang

tjujxwp@126.com

1 Tianjin Key Laboratory of High Speed Cutting and Precision Machining, Tianjin University of Technology and Education, Tianjin 300222, China

2 Key Laboratory of Mechanism and Equipment Design of Ministry of Education, Tianjin University, Tianjin 300072, China 